\title{
Gadoliniumlu MRG tetkikleri ve girişimsel nöroradyolojik u ygulamaların subaraknoid mesafeye kontrast madde sızıntısına etkisi
}

\section{Effect of interventional neuroradiological applications conducted during and after MRI examinations with gadolinium on contrast agent diffusion in subarachnoid space}

\author{
Erkan Gökçe ${ }^{1}$, Berat $\mathrm{Acu}^{2}$, Murat Beyhan ${ }^{3}$, Murat Fırat ${ }^{4}$ \\ 1 Radiology/School of Medicine/Gaziosmanpaşa University/Tokat/Turkey. \\ 2 Radiology/School of Medicine/Osmangazi University/Eskişehir/Turkey. \\ 3 Radiology/Tokat State Hospital/Tokat/Turkey. \\ 4 Radiology/Güven Hospital/Ankara/Turkey
}

OZET

Amaç: Gadoliniumlu ve iyotlu kontrast maddelerin çeşitli patolojilerde subaraknoid mesafeye (SAM) geçtiği, hemorajiyi taklit ettiği ve nörotoksiteye yol açtığı bilinmektedir. Bu çalışmada gadoliniumlu MRG tetkikleri ve karotid arter stentleme (KAS) işlemlerinin kontrast maddenin SAM'a geçisine etkisi değerlendirilmektedir.

Gereç ve yöntemler: Bu çalışma Mayıs 2009-Mayıs 2011 tarihleri arasında karotis darlığı nedeniyle TRICKS MRA ve sonrasında KAS işlemi yapılan 10 (7 erkek ve 3 kadın) hastayı

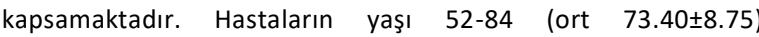
aralığındaydı. Stent yerleştirme işlemi öncesi 8 hastaya, stent işlemi sonrası ise tüm hastalara difüzyon MRG ve FLAIR sekansını içeren MRG yapıldı.

Bulgular: KAS işlemi sonrası $1.5-3$ saat aralığında alınan kontrol FLAIR sekansında 4 hastada SAM'a kontrast madde geçisi saptandı. TRICKS MRA ve KAS işlemi arasındaki süre ve iskemik lezyon varlığı ile SAM'a kontrast madde geçisi arasında anlamlı ilişki saptandı (sırasıyla $\mathrm{p}=0.011, \mathrm{p}=0.005$ ).

Sonuç: Gadolinium ve iyotlu kontrast maddelerin kullanıldığı kontrastlı MRG tetkikleri ve 24 saat içinde yapılan KAS işlemine bağlı SAM'a gadolinium geçişi görülebilir. Bu nedenle gadolinium içeren MRG tetkikleri sonrasında daha güvenli olabileceği nedeniyle iyotlu kontrast madde içeren tetkikler veya işlemlerin en azından 2 gün sonra yapılmasını önermekteyiz.

Anahtar kelimeler: karotid arter stentleme; gadolinium; iyotlu kontrast maddeler; manyetik rezonans anjiografi; subaraknoidal mesafe

\section{ABSTRACT}

Purpose: Gadolinium and iodinated contrast agents are known to enter subarachnoidal space (SAS) in various pathologies and mimicking hemorrhage and/or leading to neurotoxicity. In this study, effect of carotid artery stenting (CAS) procedures conducted during and after MRI examinations with gadolinium on contrast agent diffusion in SAS.

Materials and methods: This study included 10 patients (seven males and three females) who received time-resolved imaging of contrast kinetics (TRICKS) MRA examinations and then CAS procedures because of carotid stenosis during the period from May 2009 to May 2011. Age of the patients varied from 52 to 84 (mean 73.40 \pm 8.75 ). Diffusion MRI examination was practiced along with fluid-attenuated inversion recovery (FLAIR) sequence in eight patients before stent placement and in all patients after the stent placement.

Results: In control FLAIR sequence conducted 1.5 to 3 hours interval after CAS, contrast agent diffusion in subarachnoid space was observed in four of the patients. There were significant differences between patients who had contrast matter diffusion into SAS and who did not in terms of duration between TRICKS MRA and CAS procedure as well as the presence of ischemic lesion due to the procedure ( $p=0.011, p=0.005$, respectively).

Conclusion: Secondary complications that develop within 24 hours after CAS procedures conducted in contrast-enhanced MRI examinations using gadolinium chelates and iodinated contrast agent used in these procedures may cause gadolinium diffusion in SAS. We conclude that the iodine containing contrasted examinations and procedures can be safer when conducted at least two days after gadolinium containing MRI examinations.

Keywords: carotid artery stenting; gadolinium; iodinated contrast agents; magnetic resonance angiography; subarachnoidal space 


\section{Introduction}

Gadolinium is known to enter subarachnoidal space (SAS) in various pathologies involving breaking down of bloodbrain barrier (BBB) (1-4). It is also known that iodinated contrast agent diffuses into SAS, mimicking hemorrhage and leading to neurotoxicity (5-7). Therefore, considering the increases in cerebrospinal fluid (CSF) signal or its density after contrast-enhanced radiological examinations, wrong diagnoses and aggressive treatments should be avoided. The aim of the present study was to evaluate factors and temporal associations between diffusion and examinations or procedures that can result in contrast agent diffusion in SAS during and after contrast-enhanced magnetic resonance angiography (MRA) in patients receiving carotid artery stenting (CAS) procedures.

\section{Materials and methods}

This study included 10 patients (seven males and three females) who received timeresolved imaging of contrast kinetics (TRICKS) MRA examinations and then carotid stent placement because of carotid stenosis in our interventional radiology clinics during the period from May 2009 to May 2011. After taking the approval of local ethic committee (No: 13-KAEK-175), digital subtraction angiography (DSA), computed tomography (CT) and MR images of the patients in Picture Archiving and Communication System (PACS, $\mathrm{GE})$ were studied retrospectively. Five of the patients were given $20 \mathrm{ml}$ and other five had $40 \mathrm{ml}$ of gadobenat dimeglumin (Multihance$0.5 \mathrm{~mol} / \mathrm{L}$; Bracco, Milan, Italy) in TRICKS MRA examinations. All MR angiographies in the study were carried out using a $1.5 \mathrm{~T}$ imaging system (Signa excite HD; GE Healthcare, WI, USA). Neurovascular head and neck coils (8 Ch) were used. Contrast agent was administered using an automatic injector and a $22 \mathrm{G}$ canula in the antecubital vein at a speed of $1.5 \mathrm{ml} / \mathrm{s}$. DSA examination was performed using DSA GE Innova 3100 (Milwaukee-USA) angiography device. In all cases included in the study, carotid artery images were obtained using $10 \mathrm{ml}$ of iopromide (Ultravist300, Bayer Healthcare Pharmaceuticals, Wayne, NJ, USA) given at a speed of $5 \mathrm{ml} / \mathrm{s}$ for each carotid artery following femoral artery catheterization. Undermapping and after IV anticoagulation with heparin, the stenosis was carefully passed with a emboli protection device with 0.014 inch wire to prevent embolism. The stent system was introduced with the guiding catheter over a 0.014 inch diameter guidewire with protection filter and stent was placed into stenosed segment of the internal carotid artery. All the interventional procedures were performed with use of the Precise pro rx nitinol stent systems (Cordis Endovascular) for stent and Aviator plus rx balloon catheter (Cordis Endovascular) for angioplasty. After the stent placement a balloon dilatation catheter was inflated into the stent to closely appose the stent for about 5-10 seconds. For CAS procedure, $8 \mathrm{~mm}$ stents were used in six patients and $7 \mathrm{~mm}$ ones in four patients. In CAS procedure, total iodinated contrast agent for each patient was $300 \mathrm{ml}$ for six of the patients, $200 \mathrm{ml}$ in three patients and $400 \mathrm{ml}$ in one patient.

Diffusion MRI (DWI) examination was practiced along with fluid-attenuated inversion recovery (FLAIR) sequence in eight patients before stent placement and in all patients after the stent placement. In four patients who developed complication due to stent placement, DWI MRI along with followup FLAIR sequence was conducted. Data about demographic features, contrast agent amounts, durations between procedures, contrast matter diffusion in SAS and ischemia development after the procedures are given in Table 1. 
Table 1. Age and gender distribution of patients and amount of contrast matter used in invasive procedure, interval of FLAIR MRI, contrast matter diffusion in subarachnoid space and presence of additional lesions.

\begin{tabular}{|c|c|c|c|c|c|c|c|c|}
\hline Patient & Age & Sex & $\begin{array}{c}\text { MRA } \\
\text { contrast agent } \\
\text { (ml) }\end{array}$ & $\begin{array}{c}\text { CAS } \\
\text { contrast } \\
\text { agent } \\
\text { (ml) }\end{array}$ & $\begin{array}{c}\text { MRA-CAS } \\
\text { interval } \\
\text { (hour) }\end{array}$ & $\begin{array}{c}\text { CAS-FLAIR } \\
\text { interval } \\
\text { (hour) }\end{array}$ & $\begin{array}{c}\text { SAS } \\
\text { diffusion }\end{array}$ & $\begin{array}{c}\text { Acute } \\
\text { ischemic } \\
\text { lesion }\end{array}$ \\
\hline 1 & 68 & $M$ & 40 & 300 & 20 & 3 & + & + \\
\hline 2 & 84 & $M$ & 40 & 300 & 19 & 1.5 & + & + \\
\hline 3 & 76 & $M$ & 20 & 200 & 21 & 2 & + & + \\
\hline 4 & 75 & $M$ & 20 & 200 & 2 & 1.5 & + & + \\
\hline 5 & 77 & $\mathrm{~F}$ & 40 & 300 & 384 & 5 & - & - \\
\hline 6 & 72 & $\mathrm{~F}$ & 40 & 300 & 120 & 6 & - & - \\
\hline 7 & 78 & $\mathrm{~F}$ & 40 & 300 & 66 & 4 & - & - \\
\hline 8 & 52 & $M$ & 20 & 300 & 102 & 2 & - & - \\
\hline 9 & 80 & $M$ & 20 & 200 & 139 & 3 & - & - \\
\hline 10 & 72 & $M$ & 20 & 300 & 147 & 2 & - & - \\
\hline
\end{tabular}

FLAIR, fluid-attenuated inversion recovery; MRI, magnetic resonance imaging; MRA, magnetic resonance angiography; CAS, carotid artery stenting; SAS, subarachnoidal space

All statistical analyses were performed using Statistical Package for the Social Sciences (SPSS) version 15.0. Data is presented as percentages (\%), median or as mean \pm standard deviations (SD). Mann Whitney-U test or the Fisher exact test have been used to test the association between categorical and continuous variables. Differences were deemed statistically significant if the probability value was $<0.05$.

\section{Results}

Age of the patients varied from 52 to 84 (mean 73.40 \pm 8.75 ). In control FLAIR sequence conducted 1.5 to 3 hours interval after CAS procedure, contrast agent diffusion in subarachnoid space was observed in four of the patients (Figure 1-5). In these patients, CAS procedure was carried out 2-21 hours interval after TRICKS MRA.

The time elapsed between TRICKS MRA and stent placement was 2 to 16 days in patients without diffusion.
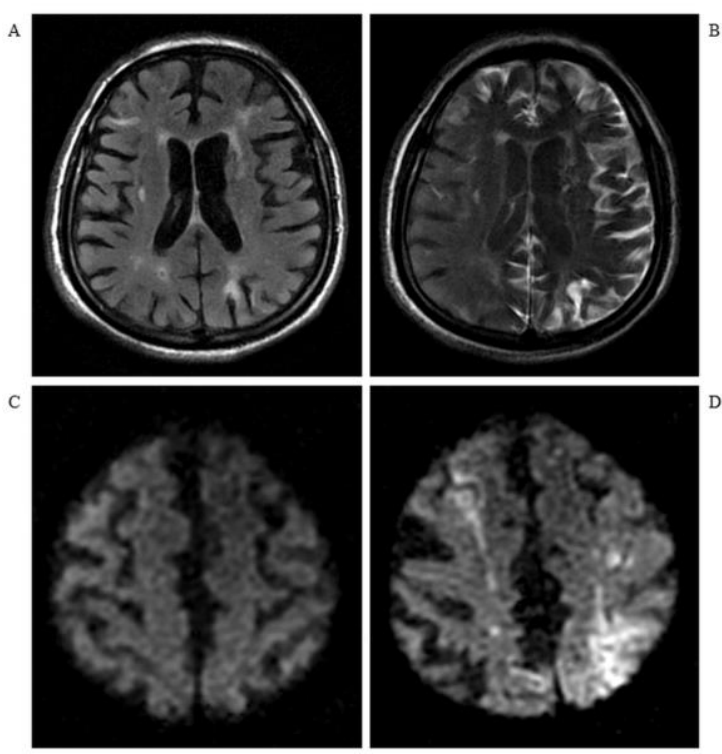

Figure 1. Seventy-five years old male patient for whom stent placement procedure was conducted in left ICA two hours after MRA and who developed permanent encephalopathy lesions. A) FLAIR sequence before stent placement procedure, B) Secondary hyperintensity to bilateral contrast diffusion more condense at left side of FLAIR sequence 90 minutes after stent placement, C) DWI before stent placement, D) Signal increase due to acute ischemia in bilateral watershed areas more pronounced in left part of DWI.

Significant differences were found between the patients who had contrast matter diffusion into SAS and who did not in terms of 
duration of the time from TRICKS MRA and stent procedure $(P=0.011)$.

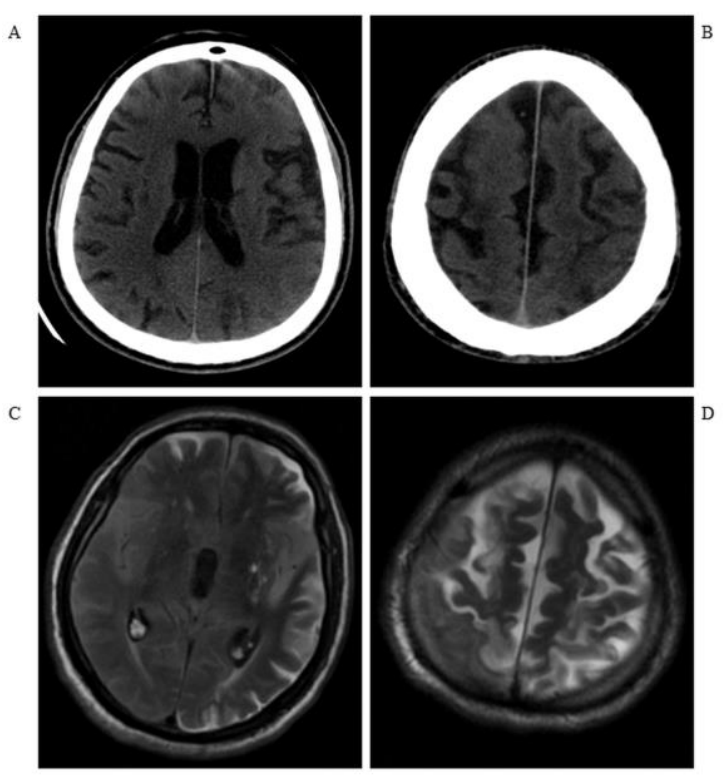

Figure 2. Seventy-five years old male patient for whom stent placement procedure was conducted in left ICA two hours after MRA and permanent encephalopathy lesions were developed. A-B) Density increase in subarachnoid space cannot be seen five hours after stent placement C-D) common hyperintensities in FLAIR MRI due to dilued gadolinium in SAS can be seen 25 hours after stent placement.
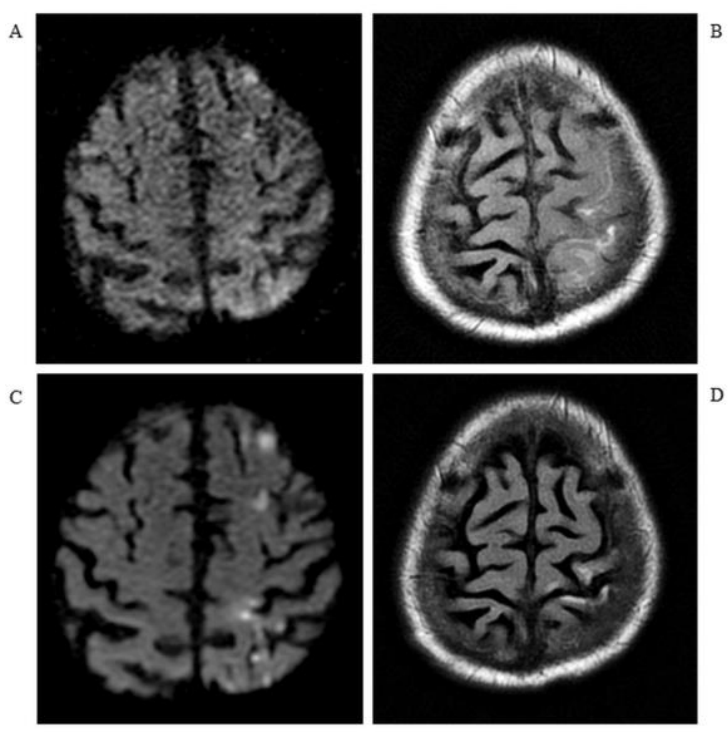

Figure 3. Sixty-eight years old male patient for whom stent placement procedure was conducted in left ICA 20 hours after MRA and a few hours lasting encephalopathy lesions were developed. Hyperacute ischemic lesions in left DWI watershed areas at three hours after stent placement. B) Hyperintensity in left SAS in FLAIR MRI on convexity plane three hours after stent placement. C) Ischemic lesions during subacute process in watershed area in DWI at the fourth day. D) Hyperintensity loss in SAS in FLAIR MRI at the fourth day.
Duration from stent procedure and post operative MRI's, on the other hand, was not significantly different between these two groups $(P=0.065)$. Average age of the patients, amounts of carotid artery stenosis and amounts of gadolinium and iodinated contrast matter used were not significantly different between these two groups $(P=$ $0.831, P=0.742, P=0.285, P=1.000$, respectively).

One of the two patients with diffusion had 90\% stenosis in contralateral ICA, while the other had occlusion. No significant differences were found between other patients with diffusion and ones without diffusion in terms of stenosis in contralateral ICAs. Ischemias were found in bilateral anterior and posterior circulation areas in the patient who had $90 \%$ stenosis in contralateral ICA, while ischemia was detected in ipsilateral posterior circulation in the patient who had occlusion in opposite ICA.

Two of the four patients who developed diffusion had central nervous system neurotoxicity lesions, while other two were asymptomatic (Figure 1-3). After stent placement, acute ischemic lesions of different sizes were observed in diffusion MRI of all patients who had diffusion. Ischemic lesions were asymptomatic (silent ischemia) in two patients, but were symptomatic in other two patients. The patients with symptomatic ischemia also had SSS neurotoxicity lesions. Contrast agent diffusion was denser in ipsilateral of ischemic lesion in two patients, while the diffusion was denser in counterlateral of the lesion in another patient. In three of the patients with diffusion, contrast agent CSF hyperintensities disappeared in control FLAIR sequences obtained in the fourth day (Figure 4, 5). The relationships between clinicopathological factors and the development of postprocedural SAS enhancement are given in Table 2. 


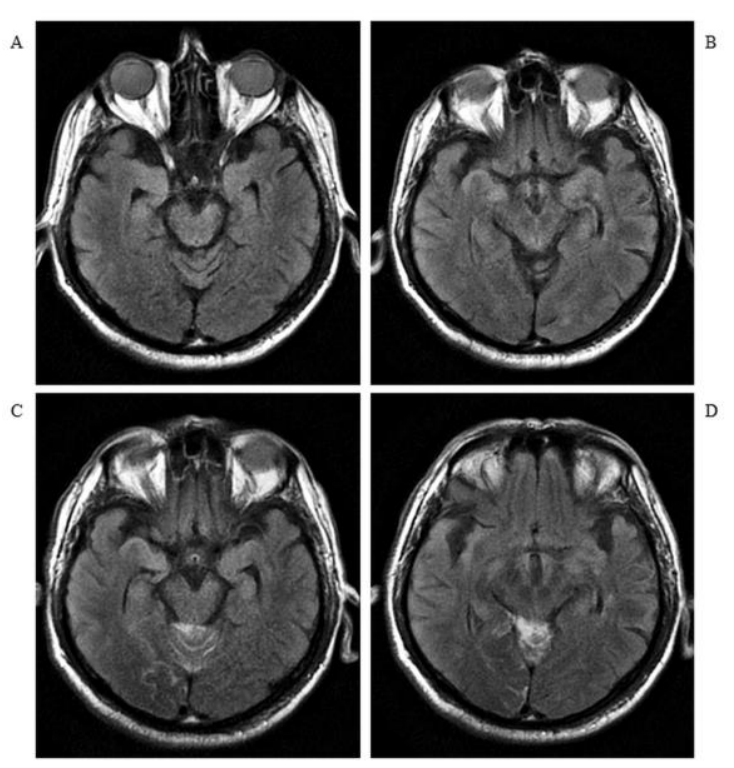

Figure 4. Seventy-six years old male patient for whom stent placement procedure was conducted in right ICA 21 hours after MRA. A-B) FLAIR MRI before stent placement C-D) hyperintensities due to contrast matter diffusion in occipital sulci on the right in superior cerebellar cistern in FLAIR MRI taken two hours after stent placement.

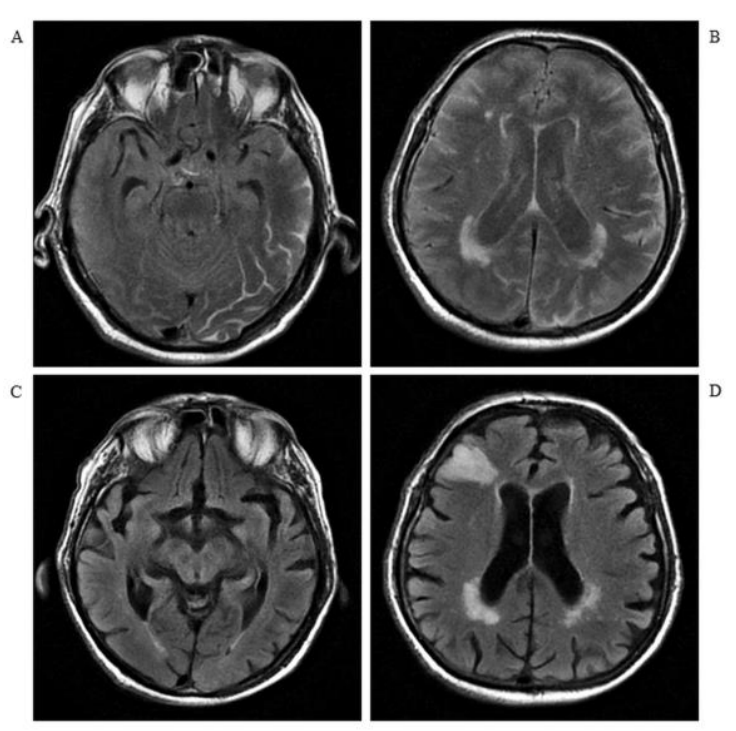

Figure 5. Eighty-four years old male patient for whom stent placement procedure was conducted in left ICA 19 hours after MRA. A-B) hyperintensity in bilateral SAS, more pronounced on the left, in FLAIR sequence 90 minutes after stent placement. CD) subacute focal ischemia developed in right middle frontal gyrus after the procedure in FLAIR MRI taken four days after stent placement. Note that SAS hyperintensities disappeared.

\section{Discussion}

Gadolinium can pass into CSF in intracranial pathologies involving BBB breakdown in amounts parallel to the degree of damage (1). Contrast-enhancing is more pronounced in CSF areas around the pathological area leading to the break-down in BBB. Gadolinium diffusion can be seen in T1 weighed images as well as in FLAIR sequence (2). Animal studies showed that FLAIR imaging is sensitive to changes in $\mathrm{T} 1$ relaxation of CSF which was observed at gadolinium concentrations of as low as $0.007 \mathrm{mmol} / \mathrm{l}$ (8). CSF hyperintensity in FLAIR sequence may develop in many different pathologies such as subarachnoidal hemorrhage (SAH), subdural hematoma, meningitis, leptomeningeal carcinomatosis, adjacent neoplasms, acute ischemic stroke and sinus thrombosis as well as in CSF flow artifacts and oxygen therapy (2, 3).

Table 2. Univariate analysis of the relationship between clinicopathological factors and the development of postprocedural enhancement of the subarachnoid space in all patients

\begin{tabular}{|c|c|c|c|}
\hline Factor of patient & $\begin{array}{c}\text { With SAS } \\
\text { enhanceme } \\
\text { nt }(n=4)\end{array}$ & $\begin{array}{c}\text { Without SAS } \\
\text { enhanceme } \\
\text { nt }(n=6)\end{array}$ & $\begin{array}{c}\mathbf{P} \\
\text { value }\end{array}$ \\
\hline Age \pm SD (yr) & $75.7 \pm 6.5$ & $71.8 \pm 10.2$ & 0.831 \\
\hline Age range (yr) & $68-84$ & $52-80$ & \\
\hline Male gender & $4(100 \%)$ & $3(50 \%)$ & 0.167 \\
\hline $\begin{array}{c}\text { Rate of stenosis } \pm \\
\text { SD } \\
\end{array}$ & $78.7 \pm 8.5$ & $76.6 \pm 12.1$ & 0.742 \\
\hline Hypertension & $3(75 \%)$ & $4(66.6 \%)$ & 0.667 \\
\hline Diabetes mellitus & $2(50 \%)$ & $2(33.3 \%)$ & 0.548 \\
\hline $\begin{array}{c}\text { Hypercholesterolem } \\
\text { ia }\end{array}$ & $2(50 \%)$ & $2(33.3 \%)$ & 0.548 \\
\hline $\begin{array}{c}\text { Postprocedural } \\
\text { ischemic symptom }\end{array}$ & $2(50 \%)$ & $0(0.0 \%)$ & 0.133 \\
\hline Contralateral lesion & $2(50 \%)$ & $0(0 \%)$ & 0.133 \\
\hline $\begin{array}{c}\text { Acute ischemic } \\
\text { lesion }\end{array}$ & $4(100 \%)$ & $0(0 \%)$ & $\underset{b}{0.005}$ \\
\hline $\begin{array}{c}\text { Postdilation } \\
\text { asystole }\end{array}$ & $1(25 \%)$ & $1(16.6 \%)$ & 0.667 \\
\hline Gadolinium (ml) & $30.0 \pm 11.5$ & $30.0 \pm 10.9$ & 1.000 \\
\hline $\begin{array}{c}\text { lodinated contrast } \\
\text { agent }(\mathrm{ml}) \\
\end{array}$ & $250.0 \pm 57.7$ & $283.3 \pm 40.8$ & 0.285 \\
\hline $\begin{array}{l}\text { Time between the } \\
\text { administration of } \\
\text { gadolinium and } \\
\text { stent } \\
\text { insertion } \pm \text { SD (h) }\end{array}$ & $15.5 \pm 9.0$ & $159.6 \pm 113.6$ & $\underset{\mathrm{a}}{0.011}$ \\
\hline $\begin{array}{l}\text { Time between the } \\
\text { stent insertion and } \\
\text { postoperative } \\
M R I \pm S D(h)\end{array}$ & $2.0 \pm 0.7$ & $3.6 \pm 1.6$ & 0.065 \\
\hline
\end{tabular}

${ }^{a}$ Calculated using nonparametric Mann-Whitney $U$ test

${ }^{\mathrm{b}}$ Calculated using Fisher's exact test

$\mathrm{MRI}$, magnetic resonance imaging; SAS, subarachnoidal space; $\mathrm{SD}$, standard deviation 
It was reported that gadolinium can pass into CSF within up to the first 24 hours in pathologies involving BBB break-down, and that pathological signal increase detected in FLAIR sequence return to normal within 2-6 days $(2,4)$. In a study by Decamber et al. (4) SAS and SAH-like signal increases were observed in FLAIR sequence of five patients who had acute ischemic lesion within the first six hours after the symptoms commenced and who had perfusion MRI examinations and FLAIR sequence within 24-48 hours. Signal increases in SAS in follow-up FLAIR sequences were reported to return to normal within 3-6 days (4). Bozzao et al. (2) reported that in patients with ischemic stroke or with lesions located close to SAS, CSF hyperintensity observed a few hours after contrast agent application in FLAIR sequence disappeared within 48 hours. In three of our cases, CSF hyperintensity disappeared in FLAIR sequence obtained on the fourth day. Nevertheless, FLAIR examinations were not available for the second and third days, so it is possible that hyperintensities might have turned to normal before the third day. Gadolinium is an extracellular contrast medium and is excreted by glomerular filtration (1). Normal half-time of gadolinium chelates is $1.3-1.6$ hours. This time can extend up to 30 hours in patients with renal impairment. In these patients, signal increases were reported in FLAIR sequence in ventricular system and aqueous humor as a result of passage of gadolinium through fenestrated choroid plexus and uveochoroid capillary membrane $(1,9)$. In one of our cases, multiple organ failure developed after stent placement. Although gadolinium was observed to be minimally dilued in SAS in FLAIR sequence of 25th hour, extensive hyperintensity was still evident (Figure 2). Follow-up FLAIR sequence taken 12 days later showed that SAS hyperintensity had returned to normal.
In a canine study by Mamourian et al. (8), gadolinium CSF concentration was shown to increase depending on intravenous dose. On the other hand, Bozzao et al. (2) found no signal increase in FLAIR sequence after gadolinium injection in normal individuals or in patients without lesions near CSF. In addition, enhancement was higher around the lesion and/or in ipsilateral hemisphere in the same patients. It was hypothesized that CSF changes develop only for lesions involving neovascularization or blood-brain barrier breakdown in the vicinity of CSF (2). Contrast agent diffusion observed in the present study in patients for whom different rates of contrast agent was used may indicate that contrast agent diffusion in SAS is not related to the amount used. Again, presence of ischemic lesion in the acute process after the procedure in all patients of the present study who had contrast agent diffusion in SAS and denser diffusion in $50 \%$ on lesion side means that diffusion first developed as a result of break-down of blood-brain barrier. However, in one of the patients, while procedure dependent focal ischemic process developed in right frontal lobe, contrast agent diffusion in SAS were more densely observed in left ICA where stent was placed. Although millimetric procedure-dependent ischemic focus was observed in right cerebellar hemisphere anterolateral of one patient who had stent in right ICA, contrast agent diffusion in SAS was observed in posteriosuperior, being more dominant on the right (superior cerebellar cistern-posterior interhemispheric fissure). This fact may indicate that stent placement procedure and iodinated contrast agent used can facilitate gadolinium diffusion in SAS. In all cases who had diffusion, a higher amount of contrast agent diffusion was observed in SAS on hemisphere side supplied by carotid artery in which stent was placed. This finding suggest that repeated high pressure iodine contrast agent applications to vascular structures on 
the side of procedure may lead to diffusion through both mechanic and physical-chemical effects (osmolality-toxic effect) on capillary wall. Although CSF chemical analysis was not performed in the present study, lack of density increase in the 5th hour brain CT of a patient, whose FLAIR sequence had contrast agent diffusion related hyperintensity three hours after stent placement and continuing hyperintensity in 6th hour follow-up FLAIR sequence, indicated that contrast agent diffused in SAS was predominantly gadolinium (Figure 2).

Ogami et al. (10) investigated 21 patients who had CAS procedure and reported that older age, higher carotid artery stenosis rate, acute stage procedure and longer neuroprotective balloon occlusion times could contribute to ischemia in BBB as factors associated with hemodynamic stability and ischemic intolerance. Average ages of 11 patients who had and who did not have diffusion in the study of Ogami et al. were $77.7 \pm 8.1$ and $70.3 \pm 5.4$, respectively, while these averages were $75 \pm 6.5$ and $71.8 \pm 6.5$, respectively, in the present study. Average carotis artery stenosis rate was $86.2 \pm 12.6$ in patients who had diffusion and $69.3 \pm 13.5$ who did not have diffusion in the study by Ogami et al. (10), whereas these values were $78.7 \pm 8.5$ and $76.6 \pm 12.1$, respectively, in the present study. Unlike the study of Ogami et al. (10), there was no significant difference between patients who had diffusion and who did not in terms of age of patients and stenosis rates in the present study.

Acute stage procedure (ischemia developing within the two-week period after the procedure) was detected in $54.5 \%$ of the patients who had diffusion in the study of Ogami et al. (10), while diffusion was detected in all patients who developed ischemia in the present study, suggesting that ischemic intolerance developing due to procedure increases the permeability of BBB. Ogami et al. (10) found that average length of duration between contrasted MRI and CAS procedure was $77.3 \pm 60.3$ minutes in patients with diffusion and $35.7 \pm 28.5$ minutes in patients without diffusion, and the difference was not significant. Unlike that study, on the other hand, average length of duration between TRICKS MRA and CAS procedure was 15.5 \pm 9.0 hours in patients with diffusion and $159.6 \pm 113.6$ hours in patients without diffusion in the present study, and the difference between these two groups was significant $(P=0.011)$. Discrepancy between these two studies suggests the need for the studies with larger series about the timing of procedures involving gadolinium and iodinated contrast matters.

Especially neuroradiologists should be aware of the fact that in patients who received gadolinium or iodinated contrast agent containing contrast-enhanced radiological examinations contrast agent diffusion into SAS or cerebral parenchyma may occur as a result of pathologies which may or may not directly lead to the breakdown of BBB. If it goes unnoticed, it could easily lead to misdiagnoses such as subarachnoidal or, sometimes intraparanchymal, hematomas and to unnecessary treatment attempts. It should be noted that especially FLAIR sequence is very sensitive to CSF signal changes. Therefore, when signal increase mimicking $\mathrm{SAH}$ is detected in FLAIR sequence following MRI examinations with gadolinium, a CT examination should be conducted to rule out hemorrhage. In addition, it should be kept in mind that contrast matters used in various ways (intravenous, intra-arterial, intrathecal) in different radiological imaging methods can result in neurotoxicity. Mechanisms by which contrast agent causes neurotoxicity should be discussed (7). Under normal conditions, 
intravenous contrast material does not diffuse in the BBB (7). But when BBB is disrupted, over dose contrast agent is applied or contrast agent is applied intra-arterially, transfer of contrast material increases (7). Contrast agent is repeatedly injected into a single vessel in neurointerventional procedures (7). In such circumstances, successive injections may contribute to BBB breakdown even when the total contrast agent amount is not excessive (7). The hyperosmolality of iodinated contrast agent leads to a shrinkage in capillary endothelium cells and open the tight junctions among them, causing an increase in permeability of BBB. Resulting increase in vesicular transport is thought to result in contrast agent diffusion in CSF and electrolyte imbalance, which in turn induces acute encephalopathy (6). Plasma osmolality equivalent contrast agents of non-ionic dimer structure, which do not lead to an inducing hyperosmolality effect on BBB, have been reported to cause transient cortical blindness and global amnesia (7). It was also reported that non-ionic monomeric and dimeric contrast agents which do not clearly contribute to osmolality in animal experiments might result in injuries in $B B B$ through various physical and chemical effects (7). In addition, extravasation of iodinated contrast agent in interstitial space can cause neurotoxicity through direct stimulation and excitation of neuronal cells (5). Encephalopathy may also develop as secondary to intrathecal or intravenous injection of gadolinium chelates (11-13). Ray et al. (11) found that total intraventricular gadolinium levels lower than $15 \mathrm{ml}(3.3 \mathrm{mM} / \mathrm{g}$ brain) do not cause behavioral or morphological changes in rats. Some studies reported that myelography and cisternography practices involving 0.25-0.50 $\mathrm{mM}$ gadolinium levels are tolerated by minor side effects such as headache (12). lodinated contrast agents and gadolinium can result in clinical neurotoxicity manifestations such as encephalopathy, seizure, cortical blindness, ataxia, weakness, myoclonus, tremor, focal neurological deficits, behavioral and psychotic disturbances $(7,11)$. In general, neurotoxic effects and radiologic lesions from contrast agents disappear after renal clearance of contrast media (5). On the other hand, cases with permanent damages due to neurotoxicities were also reported (7). In the present study, a 84 years old male patient who had contrast agent diffusion, very probably gadolinium, developed encephalopathy lesions in the form of behavioral disturbances, amnesia and agitation starting a few hours after the procedure and lasting for a few hours. In another patient who was 75 years old and had contrast agent diffusion developed permanent global aphasia after the procedure. We believe that subsequent observance of common bilateral watershed ischemia spaces and multiple organ failures might have contributed to a large extent to the development of global aphasia along with contrast agent diffusion.

Retrospective nature of our study, lack of a complete standardization of the parameters used (e.g. amount of contrast matter and time of imaging) and limited number of patients employed can be mentioned as the limitations of our study.

In conclusion, ischemic intolerance developing during CAS procedure could lead to increase in the permeability of BBB. In addition, secondary complications that develop within 24 hours after CAS procedures conducted in contrast-enhanced MRI examinations using gadolinium chelates and iodinated contrast agent used in these procedures may cause gadolinium diffusion in SAS. Therefore, we conclude that the iodine containing contrasted examinations and procedures can be safer when conducted at 
least two days after gadolinium containing MRI examinations.

\section{Conflict of interest disclosure}

The authors declared no conflicts of interest

\section{References}

1) Ong E.M, Yeh I.B. High signal in the cerebrospinal fluid following prior gadolinium administration in a patient with renal impairment. Singapore Med J 2007; 48(11):e296-8.

2) Bozzao A, Floris R, Fasoli F, et al. Cerebrospinal fluid changes after intravenous injection of gadolinium chelate: assessment by FLAIR MR imaging. Eur Radiol 2003; 13(3):592-7.

3) Morris J.M, Miller G.M. Increased signal in the subarachnoid space on fluid-attenuated inversion recovery imaging associated with the clearance dynamics of gadolinium chelate: a potential diagnostic pitfall. Am J Neuroradiol 2007; 28(10):1964-7.

4) Dechambre SD, Duprez T, Grandin CB, et al. High signal in cerebrospinal fluid mimicking subarachnoid hemorrhage on FLAIR following acute stroke and intravenous contrast medium. Neuroradiology 2000; 42(8):608-11.

5) Gürer B, Yılmaz RE, Kahveci R, et al. Non-ionic contrast media neurotoxicity mimicking intracerebral hematoma. Acta Neurochir 2011; 153:419-420.

6) Sawaya RA, Hammoud R, Arnaout S, et al. Contrast-induced encephalopathy following coronary angioplasty with iohexol. South Med J 2007; 100(10):1054-5.

7) Leong S, Fanning NF. Persistent neurological deficit from iodinated contrast encephalopathy following intracranial aneurysm coiling. A case report and review of the literature. Interv Neuroradiol 2012; 18(1):33-41.

8) Mamourian AC, Hoopes PJ, Lewis LD. Visualization of intravenously administered contrast material in the CSF on fluid-attenuated inversionrecovery MR images: an in vitro and animal-model investigation. Am J Neuroradiol 2000; 21:105-111

9) Kanamalla US, Boyko OB. Gadolinium diffusion into orbital vitreous and aqueous humor, perivascular space, and ventricles in patients with chronic renal disease. AJR Am J Roentgenol 2002; 179:1350-52.

10) Ogami R, Nakahara $T$, Hamasaki $O$, Araki $H$, Kurisu K. Cerebrospinal fluid enhancement on fluid attenuated inversion recovery images after carotid artery stenting with neuroprotective balloon occlusions: hemodynamic instability and blood-brain barrier disruption. Cardiovasc Intervent Radiol 2011; 34(5):93641.

11) Ray DE, Cavanagh JB, Nolan CC, et al. Neurotoxic effects of gadopentetate dimeglumine: behavioral disturbance and morphology after intracerebroventricular injection in rats. AJNR Am J Neuroradiol 1996; 17(2):365-73.

12) Park KW, Im SB, Kim BT, et al. Neurotoxic manifestations of an overdose intrathecal injection of gadopentetate dimeglumine. J Korean Med Sci 2010; 25(3):505-8.

13) Arlt S, Cepek L, Rustenbeck $\mathrm{HH}$, et al. Gadolinium encephalopathy due to accidental intrathecal administration of gadopentetate dimeglumine. J Neurol 2007; 254(6):810-2. 